\title{
"The whole is greater than the sum of its parts" - True, false or meaningless?
}

\author{
Esa Itkonen
}

\begin{abstract}
The slogan in the title of this article is meaningless in a context where the notion of "sum" does not apply. It is false in a context where the whole is equal to (or indistinguishable from) the sum of its parts. Having only a metaphorical meaning, it is neither clearly true nor clearly false in a context where no numerical value can be assigned to this relation of magnitude (which is typically the case in linguistics). In this article, however, a unit of measurement is devised which makes it possible to decide whether a linguistic whole is greater or smaller than the sum of its parts. In the former case the slogan is true whereas in the latter case it is, once again, false.
\end{abstract}

Keywords: holism, reductionism, compositionality, normativity, Construction Grammar, perceptual gestalts, idioms

\section{Introduction}

Two basic positions are customarily adopted vis-à-vis the issue indicated in the claim that "the whole is greater than the sum of its parts", depending on the context. Here, whole = $\mathrm{C}$ vs. its parts $=\mathrm{A}$ and $\mathrm{B}$ :

(I) "whole $=$ parts", i.e. $\mathrm{C}=(\mathrm{A}+\mathrm{B})$, where $\mathrm{C}$ is additive or reduced to $\mathrm{A}$ and $\mathrm{B}$.

(II) "whole $>$ parts", i.e. $\mathrm{C}>(\mathrm{A}+\mathrm{B})$, where $\mathrm{C}$ is non-additive or not reducible to $\mathrm{A}$ and B

Therefore, (I) may be regarded as the reductionist thesis, whereas (II) is the nonreductionist (or holistic) thesis. There are several uncontroversial examples of (I), shown in Section 2. By contrast, the exact scope of (II) remains controversial. In other words, there is no general agreement on when reduction is or is not possible (or whether it is complete rather than partial). In (II), $\mathrm{C}$ is regarded as emergent, which sometimes means that A and B are located at a lower ontological level than C. For instance, in Popper's ontology of 'three worlds', the social-normative World-3 is emergent vis-à-vis the individual-psychological World-2 just as this is in turn emergent vis-à-vis the physical World-1.

Within Cognitive Linguistics, there is - or at least seems to be - an opposition between (I) and (II). On the one hand: "A nonreductionist theory [such as Radical Construction Grammar, or $\mathrm{RCxG}$ ] differs from a reductionist theory in that it hypothesizes that the whole is greater than the sum of its parts" (Croft, 2001, p. 48; emphasis added). "In accord with the non-reductionist nature of $\mathrm{CCxG}$ [Cognitive Construction Grammar] and $\mathrm{RCxG}$, both approaches emphasize that there are often interactions between parts that lead to emergent properties that can only be described at the level of the whole" (Goldberg, 2006, p. 222; emphasis added).

On the other hand, Langacker's Cognitive Grammar [CG] would seem to be in line with (I): "Like water (a particular configuration of hydrogen and oxygen atoms), [grammar] is however reducible to something more fundamental (configurations of semantic structures, phonological structures, and symbolic links)" (Langacker, 2003, p. 
89; emphasis added).

The issue is, however, more complex as a kind of reduction is also accepted by Goldberg (2006, p. 222): "In some sense, water is clearly reducible to hydrogen and oxygen; however, no reductionist account of water is going to explain why water is wet, nor why it is used in the way it is: to bath in, to drink, etc." Nor should we forget that Langacker (1987) characterizes Cognitive Grammar as "a non-reductive approach to linguistic structure" (p. 494; emphasis added), or again as "maximalist, nonreductive, and bottom-up ... (as compared to the minimalist, reductive, and top-down spirit of the generative tradition)" (1991, p. 264; emphasis added); and he also speaks of "the nonreductive character" of the CG-type phonological analysis (p. 272). Thus, at any rate, CG is less reductive than generative grammar. In other words, it looks like (non)reductionism is a matter of degree. Clearly, this issue is in need of some conceptual clarification, which is the primary aim of this article.

In Section 2, I provide a number of examples from different domains where the issue of whether the "whole" can be reduced to the "parts" is relevant. In Section 3, we look in more detail into a number of conceptual problems that require attention before proceeding. Section 4 is the main one in the article, focusing on "parts and wholes" in language and linguistics, and delving into specific issues like (semantic) compositionality, lexical and grammatical meanings, idioms, normativity and predictability. Section 5 summarises the discussion, and answers the question in the title: it turns out that the non-reductive thesis is indeed in some cases "true", in others "false", and in still others "meaningless".

\section{Exemplifying (I) "whole = parts" vs. (II) "whole $>$ parts"}

It is the purpose of this section to familiarize the reader with the (I) vs. (II) opposition by means of a few representative examples. Before doing so, however, a few preliminary remarks have to be made. First, there are domains like shape, density, and elasticity where the notion of "sum" is meaningless and where, therefore, neither (I) nor (II) is true (or false) (Nagel, 1961, p. 385).

Second, because (II) claims $\mathrm{C}$ to be more than $(\mathrm{A}+\mathrm{B})$, there ought to be a way to compare $\mathrm{C}$ and $(\mathrm{A}+\mathrm{B})$ so as to assign respective numbers $n-1$ and $n-2$ to $\mathrm{C}$ and $(\mathrm{A}+\mathrm{B})$ such that $n-1>n$-2. Interestingly, this requirement is never fulfilled. In the absence of any units of measurement, the cognitive significance of (II) is comparable to statements like John has a greater personality than Bill. Has (II), then, any genuine substance? This question becomes even more urgent when we realize that (II), as originally formulated by Max Wertheimer, is "The whole is different from the sum of its parts", which indeed makes more sense (Goldstein, 1989, pp. 23, 194). Hence, in the name of accuracy, we must distinguish between the "whole $>$ parts" thesis and the "whole $\neq$ parts" thesis.

Third, the fact that up to now no numerical "whole vs. parts" comparisons have been made does not mean that they cannot be made. In linguistics it is in effect possible to determine quite exactly how much a whole is greater than the sum of its parts, as shown in Section 4.2. Fourth, and finally, the possibility of "whole $<$ parts" is generally ignored but it should also be taken into account, as argued in Section 4.4.

\subsection{Geometry and mathematics}

In geometrical and mathematical contexts the (I) thesis is regarded as an "an analytic or necessary truth" (Nagel, 1961, p. 381, 384). For instance, a circle is identical with the sum of its two halves. More generally, (I) is true of scalar sums: numerosity, space (= 
length, area, volume), time, weight, heat, electric charge and resistance. These are all clear examples of (I). Furthermore, (I) may be extended to vector sums as well: forces, velocities, and accelerations. For instance, a force of 3 due north and another force of 4 due east produce a single force of 5 due north-east (ibid, p. 386).

\subsection{Music}

Next, let us examine the issue from the musical point of view. Consider this statement: "A melody is more than the sum of its individual notes." Is it true or false? Nagel (1961, p. 388) gives the following sensible answer: "the statement can be established as true or false only if it possible to compare such a sum with the whole that is the melody". In general, the proponents of thesis (II) do not specify what they mean by "sum" in this type of context. Nagel sees two possibilities: either they want to say that the "whole > parts" thesis is here meaningless (but have just chosen a wrong way to say it); or they use the word "sum" to refer to the unordered set of the individual notes/tones. On the latter interpretation, we have to do with the familiar opposition between unordered (1) and ordered sets (2), e.g. triples.

(1) $\quad\{\mathrm{x}, \mathrm{y}, \mathrm{z}\}$

(2) $\langle\mathrm{x}, \mathrm{y}, \mathrm{z}\rangle$

Three things need to be noted about the (1) vs. (2) opposition. First, there is no way to 'reduce' (2) to (1), which entails that (2) is, technically speaking, "emergent" vis-à-vis (1). Second, although (2) is felt to be "more" (i.e. more structured) than (1), there is no numerical sense in which this difference can be expressed. Third, considered as a whole, (2) consists in nothing but $x$ standing is a certain relation to $y$ ("first this, then that"). It is not the case that (2) has some emergent property in addition to this relation. It is this relation alone which renders (2) "more" vis-à-vis (1).

The general (1) vs. (2) opposition may be exemplified by a musical example as in (3) vs. (4).

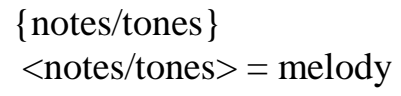

$$
\langle\text { notes/tones }>=\text { melody }
$$

Nagel's (1961) comments on the (3) vs. (4) distinction deserve to be quoted: "if the word 'sum' is used in this sense in contexts where the word 'whole' refers to a pattern or configuration formed by elements standing to each other in certain relations, it is perfectly true though trivial to say that the whole is more than the sum of its parts" ( $p$. 388; emphasis added). "A melody [ought to] be viewed as a relational complex whose component tones are identified independently of their occurrence in that complex" ( $p$. 399). Thus, each side of the $\{$ list $\}$ vs. <structure> opposition has its own justification.

The foregoing can be summarized by saying that there is an analogy between (1) vs. (2) and (3) vs. (4), formalized as (1):(2) = (3):(4). Notice, however, that the $\langle\mathrm{X}\rangle$ notation, which is borrowed from the set theory, serves here as a metaphor for structure ("pattern", "configuration") in general, while $\{X\}$ stands for the heap of the disconnected parts that $\langle\mathrm{X}\rangle$ contains. 


\subsection{Language (preliminarily)}

The analogy shown above may be extended to linguistic data as in (5) and (6).

(6) $\quad<$ men, drink, beer $>=$ (sentence-)structure

Example (6) is the (correct) English sentence Men drink beer, while (5) is the (unordered) list of the words that constitute (6). Clearly, there is no way to reduce (6) to (5), which means that (6) is emergent vis-à-vis (5). It goes without saying that $\{X\}$ and $\langle X\rangle$ are different. But is $\langle\mathrm{X}\rangle$ more than $\{\mathrm{X}\}$ ? If an affirmative answer just repeats the structured vs. disconnected opposition, that would be rather trivial. However, as I argue in Section 4 , there is an additional, and much more substantial sense in which thesis (II) applies here.

\subsection{Institutions}

Let us mention one more analogy evoked by the (1) vs. (2) opposition. As documented by O'Neill (1973), there has been in the philosophy of social sciences a long-standing debate between proponents of individualism vs. collectivism (or holism): Can social entities like institutions (= "wholes") be reduced to actions and thoughts of individual persons (= "parts")? Or do we have to postulate, in addition, the existence of some "over-individual" entities? The obvious answer seems to be that both sides are right. On the one hand, there is nothing over and above individual persons (plus some institution-related equipment). On the other, these are persons standing in a definite network of relations to one another: what we have is a structured whole (8), not a random aggregate of individuals (7) (Itkonen, 1978, pp.127-131, 2008, pp. 290-291).

$$
\begin{aligned}
& \{\text { individuals }\} \\
& <\text { individuals }>=\text { institution }
\end{aligned}
$$

The notion of typical person (= social role) shows how actual individuals are integrated into the relevant institution. Consider the following analogy: analyzing a drama as a whole is the same thing as analyzing it as a web of the roles played by the ("real") actors, in brief: <roles> = drama (Ryan, 1970, pp. 177-179). Durkheim (1973[1901]) seems to repeat the (7) vs. (8) opposition:

\footnotetext{
la société n'est pas une simple somme d'individus, mais le système formé par leur association représente une réalité qui a ses caractères propres. ... Il faut encore que ces consciences [particulières] soient associées, combinées, et combinées d'une certaine manière: c'est de cette combinaison qui résulte la vie sociale et, par suite, c'est cette combinaison qui l'explique" (pp. 102-103; emphasis added). ${ }^{1}$
}

But there is a twist. Durkheim is a fervent proponent of the "whole > parts" position: "C'est qu'un tout n'est pas identique à la somme de ses parties, il est quelque chose d'autre et dont les propriétés diffèrent de celles que présentent les parties dont il est composé" (ibid, p. 102). ${ }^{2}$ With respect to the social vs. individual dichotomy, "he was

\footnotetext{
1 "Society is not just a sum of individual persons. Their association constitutes, rather, a system which represents a reality of its own. ... All these consciousnesses must be associated and combined in a certain way: it is this combination which produces the social life and hence explains it."

2 "A totality is not identical with the sum of its parts; it is something else, and its properties are not those of its parts."
} 
single-mindedly, almost fanatically preoccupied with demonstrating the reality of the former" (Lukes, 1975[1973], p. 34). It follows that he places institutions (like language or currency) on an ontological level of their own: they are external to the individual who is totally unable to resist their "power of coercion". This is why he thinks that the direction of explanation must go from social to individual/psychological, never the other way around. It is easy to show, however, that in some crucial respects this intransigent position is flatly contradicted by his own descriptive practice (ibid, pp. 16-22; also Itkonen, 1983, pp. 91, 96-97).

\subsection{Chemistry}

Next, let us consider the prototypical example of emergence: Is water (nothing but) $\mathrm{H}_{2} \mathrm{O}$ ? The standard scientific answer is affirmative: water is reduced to hydrogen and oxygen, which means that it exemplifies thesis (I). But there is also a dissenting view. For instance, to support his strict "social vs. individual" dichotomy, Durkheim looked for analogies in other domains: "the hardness of bronze is not found in copper and tin, nor the properties of water in hydrogen and oxygen" (Lukes, 1975[1973], p. 20). Indeed, it is universally agreed that water has properties (like viscosity and translucency) that cannot be predicted from the properties of hydrogen alone or oxygen alone or of compounds where one or the other occurs (Nagel, 1961, pp. 368-369). This clearly suggests that water is an emergent phenomenon and thus exemplifies thesis (II).

Indeed, it is undeniable that here the whole is different from the sum of its parts. By contrast, it is not at all clear why the whole should also be more than the sum of its parts. The combination $\mathrm{C}$ (= water) gains properties that neither $\mathrm{A}$ (= hydrogen) nor $\mathrm{B}$ (= oxygen) has alone. But it is practically never mentioned that, by the same token, $\mathrm{C}$ loses some properties of A and/or B (like hydrogen being in a gaseous state under certain conditions of pressure and temperature). Thus, the term more (or less) seems here to be used metaphorically, rather like the example of John having a "greater" personality than Bill, given at the beginning of the section.

Is water a good analogy for language? Or, to put it in simplistic terms, are hydrogen and oxygen to water what noun and verb are to sentence? I do not think so. At least, I prefer the analogy between (3) vs. (4) and (5) vs. (6). Compared to a sentence or melody, water seems to be more emergent. Notice that in this particular instance the use of "more" is not just metaphorical but can be justified be referring to tangible changes that occur in moving from parts to wholes, while there is much less tangible difference between verb and sentence.

If a linguistic analogue has to be found for water, then - as de Saussure (1962[1916]) pertinently notes - one should perhaps think of the linguistic sign. It is a unity whose constituents, i.e. form (signifiant) and meaning (signifié), are comparable to hydrogen and oxygen insofar as "pris à part, chacun de ces éléments n'a aucune des propriétés de l'eau" (p. 145). By contrast, there are many properties that nouns and, in particular, verbs share with sentences.

Several definitions have been proposed for emergence, some of which are quite technical (e.g. Beckerman et al. 1992). In the present context it is enough to rule out the most obvious definition which equates "emergent property" with "property that can only be defined at the level of the whole". We have agreed that a circle is the sum of its two halves, but clearly a circle has properties (like "completely round") which half a circle lacks. Or consider such a whole as the string of letters SKDL. It can be partitioned in many different ways, but none of its possible parts has the property "contains four

3 "Taken in itself, each of these elements lacks the properties of water." 
letters". Does this mean that SKDL is emergent? No, unless every whole is "emergent" by definition.

\subsection{Perceptual gestalts}

Traditionally, this is where the strongest support for thesis (II) comes from: "The paradigm example of a nonreductionist theory is the theory of perception proposed by the Gestalt psychology" (Croft, 2001, p. 47). This surely sounds plausible.

The basic insight has been described as follows: "This sequence of flash-darknessflash causes a phenomenon called apparent movement - the perception of movement from left to right through the dark space separating the two flashed lights. How, asked Wertheimer, is it possible to explain our perception of a line moving through the dark empty space in terms of sensations? Since there is no stimulation whatsoever in that space, there are no sensations present to provide an explanation ... and the phrase 'The whole is different from the sum of its parts' became the battle cry of the Gestalt psychologists" (Goldstein, 1989, pp. 22-23; the second emphasis added). Demonstrations like this justified "the idea that the stimulus must be considered as a whole" (p. 194).

In apparent movement, something is perceived which is not there. The same phenomenon recurs in the so-called "phonemic restoration effect": a sound which is masked by white noise $(=\bullet)$ is nevertheless perceived, for instance the vowel /o/ upon hearing the word-like stimulus [pr•gress] (ibid, pp. 465-466). It seems natural to say that here the whole is more than the sum of its parts. Yet there is reason to question the justification of this well-entrenched expression.

Let us simplify the auditory example: two sounds $\mathrm{A}$ and $\mathrm{B}$ are given, but three sounds are heard, namely a word $\mathrm{C}$, where $\mathrm{C}=(\mathrm{A}+\mathrm{D}+\mathrm{B})$. Clearly, the whole $(=\mathrm{C})$ is greater than the sum of its parts $(=\mathrm{A}+\mathrm{B})$, is it not? No, it is not. There is a mistake in this argument. The parts $\mathrm{A}$ and $\mathrm{B}$ are physical elements, but these are not the parts that the whole $\mathrm{C}$ contains. Rather, $\mathrm{C}$ contains the psychological elements A', D', and B'. One may be tempted to say that $\left(\mathrm{A}^{\prime}+\mathrm{D}^{\prime}+\mathrm{B}^{\prime}\right)>(\mathrm{B}+\mathrm{C})$, but this would be a mistake, like comparing apples and oranges. Hence, if "the parts" stand for the stimuli, the whole is not greater than the sum of its parts. (Nor is it smaller.) At the perceptual level, on the other hand, the whole is equal to the sum of its parts: $\mathrm{C}=\left(\mathrm{A}^{\prime}+\mathrm{D}^{\prime}+\mathrm{B}^{\prime}\right)$.

To put it differently, two different kinds of wholes are involved here, physical and psychological, and the Gestaltist argument amounts to the confused claim that the psychological whole is greater than the sum of the parts of the physical whole (Phillips, 1976, pp.117-118).

In general, the "whole > parts" thesis is neutral as to the synchronic vs. diachronic distinction. The most obvious justification for postulating emergent properties comes from the domain of evolution: the transition from single living cells to animals must contain an enormous amount of changes big enough to qualify as emergent. For simplicity, the evolutionary point of view will be ignored here. But adopting the process point of view may supply additional clarification. Accordingly, the argument of the preceding paragraph may be summarized as follows:

$$
\begin{array}{llll}
(\mathrm{A}+\mathrm{B}) \\
\mathrm{C}=\left(\mathrm{A}^{\prime}+\mathrm{D}^{\prime}+\mathrm{B}^{\prime}\right)
\end{array} \quad \rightarrow \quad M \quad \rightarrow
$$

The human perceptual mechanism $\mathrm{M}$ receives $\mathrm{A}$ and $\mathrm{B}$ as an input and produces C, i.e. (A' + D' + B'), as the output. It goes without saying that any M must change its input in some way, as it makes no sense to construct or postulate a "mechanism" which leaves the input entirely untouched (i.e. with input $=$ output). In the present case M turns 
physical data into perceptual data. The same argument applies to the emergence of apparent movement: input $=$ two stationary flashes of light vs. output $=$ perceived motion . In sum, and against all expectations, thesis (II) appears to receive no genuine support from Gestalt psychology.

\section{Conceptual issues}

As the examples in the previous section show, some "obvious" cases of holism (thesis II) presented in the literature are not that clear, and when these are applied analogically to language, the level of clarity decreases still. Hence, before we turn more specifically to language in Section 4, we will need some more conceptual clarification.

\subsection{The definition of "sum"}

Let us recall that the contrast between (I) and (II) is meaningful only to the extent that it is possible to specify what is meant by "sum". Having discussed scalar and vector sums, Nagel (1961) proposes the following maximally general definition: "the 'sum' of a given set of elements is simply an element that is uniquely determined by some function (in the mathematical sense) of the given set" (p. 387). In this technical sense, not just 8 but also 4 is a "sum" in these examples:

$$
\begin{aligned}
& +(6,2)=8 \\
& -(6,2)=4
\end{aligned}
$$

Now, transitive verb (V-tr), for instance, may be defined as a two-place function which takes a pair of nouns as its arguments and yields sentence $S$ as its value, as in (13).

$$
\mathrm{V}-\operatorname{tr}(\mathrm{N}-1, \mathrm{~N}-2)=\mathrm{S}
$$

On this interpretation, then, $S$ is the 'sum' of $N-1$ and $N-2$. But notice that if manyplace functions are redefined as successions of one-place functions, as in (Montaguetype) categorical grammar (Itkonen, 1983, pp. 144-145), this notion of "sum" seems to become meaningless, because we are no longer dealing with a "set of elements" (= arguments). Yet this consequence can perhaps be avoided by arguing that we really have to do here with many-place functions, given that there are other one-place functions (like "to the power $n$ ") as well which are implicit many-place functions (here: multiplications).

Unfortunately, the mathematical definition is not suitable to cover those cases that are the most interesting from the linguistic point of view. Therefore, in what follows, the term "sum" will designate the number of the (disconnected) units in a $\{$ list $\}$, with the understanding that these are identical with the relevant parts of a corresponding <structure>, as elaborated below.

\subsection{The relativity of "whole vs. parts"}

The simple "list vs. structure" dichotomy may be replaced by the trichotomy "no structure (= list) vs. flat structure vs. hierarchical structure". The "no structure" option is explained by Ryan (1970, p. 181): "That the whole is not merely the sum of its parts is clear as soon as one reflects on the difference between a motor which is assembled and ready to run and a motor which is stacked in components on a shelf." This repeats the distinction between $\{x, y\}$ and $\langle x, y\rangle$.

Let us stipulate that $\{x, y\}$ has disconnected parts whereas $\langle x, y\rangle$ has integrated 
parts. The sum of the disconnected parts is 2 , and we have already established in Section 2.2 that this type of sum is always less than the whole (in some intuitive sense of "less"). But now we must ask: What is the sum of the integrated parts? Interestingly, this may not be a meaningful question. The answer cannot be 2 because, as we just saw, this is the sum of the disconnected (= un-integrated) parts. But any other answer - like 3 or 4 - seems equally unjustified. Furthermore: if (as we have agreed) the sum of the disconnected parts, i.e. 2, is less than the whole, what is then the number that correctly characterizes the whole? Again, any specific answer - like 3 or 4 - seems meaningless. Finally: assuming that the "sum of the integrated parts" is a coherent notion, does it in any way differ from the whole, i.e. $\langle x, y\rangle$ ? A negative answer was suggested e.g. by the "institution = drama" analogy in Section 2.4.

In order to illustrate the distinction between flat and hierarchical structures, Simon (1962) uses a parable that has subsequently been made famous by Koestler (1967, Chap. III) and Sampson (1980, Chap. VII). A and B are persons who make watches with an equal number of parts (e.g. 1000), but A proceeds by combining elementary parts with one another whereas B proceeds by stages: first, a set of 10 elementary parts is assembled into a second-level unit; next, this is repeated 99 times; next, a set of 10 second-level units is assembled into a third-level unit; next, this is repeated 9 times; finally, the set of 10 third-level units is assembled into one fourth-level unit which is identical with a complete watch (with 1000 elementary parts). The two types of watches are described, respectively, by a (linear) string and by a (hierarchical) tree.

Simon's parable is based on the assumption that string-like structures are unstable whereas tree-like or hierarchical structures are stable: if the process of assembly is interrupted e.g. when A is handling the $947^{\text {th }}$ part, A must go back to the beginning and start anew, whereas it is enough for B to go back to the intermediate unit s/he was working with. Assuming that disturbances intervene now and then, completed flat structures are bound to occur with a very much lower probability than completed hierarchical structures. This is where biological evolution produces results analogous to those produced by rational planning. Sampson (1980, p. 172) seems justified to claim that if sentences had no hierarchical structure, language-acquisition would be impossible.

Let us consider a simple example like (6), i.e. Men drink beer. Presented as a tree, it exhibits three levels of form i.e. clause > word > sound. (For simplicity, the NP and VP levels are ignored here.) Clauses consist of words, which consist of sounds, which consist of (articulatory) features, as shown in Figure 1.

Clause

Word

Sound

$$
\text { <men, drink, beer> }
$$

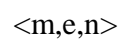

$\langle\mathrm{b}, \mathrm{e}, \mathrm{e}, \mathrm{r}\rangle$

$\langle\mathrm{d}\rangle\langle\mathrm{r}\rangle\langle\mathrm{i}\rangle\langle\mathrm{n}\rangle\langle\mathrm{k}\rangle$ $\langle\mathrm{b}\rangle\langle\mathrm{e}\rangle\langle\mathrm{e}\rangle\langle\mathrm{r}\rangle$

Figure 1. Three levels of form/function in a sentence

Each one of the levels in Figure 1 has its own function. ${ }^{4}$ The clause expresses a speech act which, being an assertion, is characterized by a truth-value. Words signify the "furniture" of language-external reality. Sounds have according to Trubetzkoy (1958[1939], p. 29) three principal functions, namely distinktiv (= bedeutungsunterscheidend), kulminativ,

\footnotetext{
4 "Structure is based upon, or determined by, function. This also explains, incidentally, why it is in practice nearly impossible to keep 'structuralism' and 'functionalism' apart” (Itkonen, 2005a, p. 2).
} 
and delimitativ. As applied to sounds, of course, the $\langle\mathrm{X}\rangle$ notation implies no intrinsic order.

From the purely formal/physical point of view, it is perhaps conceivable to "reduce" the higher levels to the lower ones, or to think that a spoken utterance is "nothing but" a string of sounds. From the functional point of view, however, this makes no sense at all. It is impossible to 'reduce' the truth-value creating capacity of a clause to phonological oppositions such as $/ \mathrm{m} / \mathrm{vs}$. $/ \mathrm{p} /$ that create the meaning difference between e.g. men and pen. (To be sure, the function of asserting can, on one interpretation, be at least divided into the subfunctions of referring and predicating.)

Koestler (1967, p. 54) makes a sensible distinction between "dissecting" (= analyzing) a whole and "reducing" it. The former is a necessity while the latter is controversial. Erdman and Stover (1991, p.12) make an analogous distinction between "methodological" and "epistemological" reductionism. To the extent that over-zealous supporters of holism wish to deny the possibility of any kind of analysis, we could reply as the psychologist James Jenkins once put it: "We can't regard a sentence as a holistic, unanalysable unit, as the Gestaltists might maintain one should" (quoted from Koestler, 1967, p. 49). At the same time, analysis does not imply epistemological, or even less ontological reductionism.

The Janus-like nature of units located at intermediate hierarchical levels is emphasized by Koestler (1967, Chap. III): seen "from below", a word is a whole while seen "from above", it is a part. This emphasis becomes more comprehensible when we consider the original hierarchy given by Simon (1962): book > chapter > section > paragraph $>$ (complex) sentence $>$ clause $>$ word $>$ syllable $>$ letter. Certainly the organizing principles of a book are not those of a syllable. Notice also that each book has its own context, which constitutes the next higher level in the hierarchy; and "the hierarchy of environments can be extended indefinitely" (Koestler, 1967, p.102).

One of the most comprehensive hierarchies has been described in the Vākyapadīya ('Book on Sentences and Words') by Bhartrhari (c. 500 AD). At the top there is Brahman (= 'the One', 'Ground of the Universe') while at the bottom there are details of allophonic variation in Sanskrit. The top and the bottom are connected as follows. The One is divided into space and time; these are subdivided into states of affairs; these are in turn analyzed into actions and participants ("things"); participants exemplify semantic roles defined by each respective action; semantic roles and actions are meanings expressed by nouns and verbs; finally, meanings are gradually replaced by forms in accordance with the general structure of Pānini's grammar (Itkonen, 1991, pp. 79-83).

When undertaking a phonological description, for instance, it is impossible to always take the entire universe into account. So it becomes vitally important to establish a descending series of less and less comprehensive sub-wholes (preliminarily illustrated by the "book $>$... letter" hierarchy). But how are we to draw the line between genuine and spurious wholes? This question will be addressed in Section 3.4.

Up to now, it has been taken for granted that "whole" must be understood in the syntagmatic sense, in the direction from big to small. There are also paradigmatic wholes, exemplified by phonological systems and declensions/conjugations. Still, the syntagmatic sense can be taken as the primary one.

\section{3 "Whole vs. parts" and analogy}

Analogy may be defined as structural similarity (Itkonen, 2005a). Two or more wholes A, $\mathrm{B}$, etc. are analogous if (and only if) they share some common structure X; and this is the 
case if (and only if) A has the same number of parts as B, i.e. parts which stand in the same (or similar) relation to each other as do the parts of B. ${ }^{5}$ It is not only the case that the "whole vs. parts" opposition is constitutive of the very idea of analogy (Itkonen, 2005a, pp. 1-3). It is also the case that analogy presupposes the truth of the "whole = parts" thesis in the "methodological" sense in which it must be possible to analyze a whole into its integrated parts, as pointed out above.

Analogies exist in all knowledge domains. Linguistic analogies are based either on form alone or on meaning alone or on both at the same time. For instance, all three-vowel systems with $/ a /, / i /, / u /$ are (formally) analogous irrespective of details of phonetic realization. Semantic analogies are exemplified in German by such lexical proportions as Vater : Mutter = Sohn : Tochter (Paul, 1975[1880], p. 107). Well-known examples of form-meaning analogies are provided by inflectional paradigms, e.g. Tag-ø : Tag-es : Tag-e = Arm- $\phi:$ Arm-es : Arm-e, which exemplify NOM.SG - GEN.SG - DAT.SG in German (ibid, pp. 107-108). In just the same way, entire sentences share a common formmeaning structure (Muster). For instance, the interrogative structure $V N$ ?, with a preposed predicate, is exemplified by such sentences as spricht Karl? and schreibt Fritz? This is easier to understand once these sentences are reformulated as spricht : Karl = schreibt : Fritz (p. 109). The form-meaning situation is captured by Sapir's (1921, p. 38) statement that "analogous concepts and relations are most conveniently symbolized in analogous forms", which he calls "a universal trait of language".

According to Paul (p. 109), all syntactic functions derive only from such analogical equations. This view was reformulated e.g. by Jespersen (1965[1924]) as follows: "What is essential is that in pronouncing it [= a new sentence] he [= the speaker] conforms to a certain pattern. No matter what words he inserts, he builds the sentence up in the same way, and even without any special grammatical training we feel that the two sentences John gave Mary the apple and My uncle lent the joiner five shillings are analogous, that is they are made after the same pattern. In both we have the same type" (p. 19; emphasis added).

The analogy-based (ditransitive) pattern adduced by Jespersen has been meticulously investigated by Goldberg (1995) as "ditransitive construction". In particular, a clear distinction is made, e.g. on p. 50, between semantics and syntax (i.e. 'causereceive <AG REC PAT>' vs. 'V SUBJ OBJ OBJ2'). It is in this same spirit that Goldberg $(1995,2006)$ and Croft (2001) also redefine what has traditionally been called intransitive vs. (mono)transitive sentence structures or patterns.

We saw in Section 1 that Construction Grammar theorists tend to favour the "whole $>$ parts' view. Apparently it has been taken for granted that the list of the disconnected parts $\{x, y, z\}$ is not just different from but also "less" than the functioning whole $\langle x, y, z\rangle$. As shown in Section 2, this is a trivial truth.

On the other hand, if the parts are considered not as a list, but as integrated into a functioning whole, then the justification of the "whole > parts" view disappears. Let us illustrate. In Yoruba, verbs and nouns are typically (though not exclusively) characterized by distinct syllabic structures, for instance: $p a$ ('to kill'), rà ('to sell'), le ('to be hard') vs. apá ('arm'), ẹni ('person'), ògiri ('wall'). Thus, considered as grammatical meanings, verb and noun are expressed by the corresponding gestalts:

$$
\begin{aligned}
& \text { verb }=\mathrm{CV} \\
& \text { noun }=\mathrm{VCV}(\mathrm{VC})
\end{aligned}
$$

\footnotetext{
${ }^{5}$ The common structure X can just as well be called "schema" or "construction".
} 
The difference between (14) and (15) is exhaustively described by means of the following three features: (i) quality = consonant vs. vowel; (ii) order = before vs. after; (iii) number $=2$ vs. 3 (or 5). In particular, (14) and (15) have no "emergent property" (or "holistic residue") over and above what can be said by means of (i)-(iii). What is true of (14) and (15) can be generalized to all constructions and wholes.

So, prior to deciding between "whole = parts" and "whole $>$ parts", we need to make it clear whether we are speaking of disconnected or integrated parts. The popularity of the "whole > parts" view seems in part to be based on the inability to distinguish between these two notions.

\subsection{Additional problems of interpretation}

On the one hand, the parts of a genuine whole have many relations and properties, some of which are relevant while others are not (Phillips, 1976, pp. 9-10): a battalion is defined by the chain of command, not by whether some of its members like music more than others. On the other hand, the existential status of wholes ranges from genuine to spurious.

\subsection{1 "The whole determines the identity of any of its parts"}

The thesis given as the title of this subsection is often lumped together with the "whole > parts" thesis, but in reality they are two different things. The truth of this new thesis is often self-evident, as when the linguistic context determines the meaning (= identity) of an ambiguous unit as in (16).

\section{John's friend smoke-s cigar-s.}

The English suffix $-s$ has three distinct meanings (i.e. GEN, PL, 3SG), each of which occurs in (16); and in each case the identity of $-s$ is determined by the larger (syntagmatic) context (= word, phrase, or sentence). This example is uncontroversial.

It may be harder to decide to what extent the identity of a non-ambiguous (lexical) unit depends on the changes in its syntagmatic context. Let us consider a sentence made famous by Goldberg (1995).

Sam sneezed the napkin off the table.

Here an intransitive verb is used in a caused-motion construction, on the analogy of transitive verbs like to push. On the one hand, this new context (= "whole") changes the identity of to sneeze (= "part") in a predictable way, namely from intransitive to transitive; on the other, it still remains the same verb (apart from the intransitive/transitive variation).

The so-called où tout se tient ('where everything is connected') principle is the lasting legacy of structuralism. It says that (linguistic) units must not be considered in themselves, or atomistically, but in relation to each other or as parts of a larger (paradigmatic) whole, which in consequence determines their identity: "c'est du tout solidaire qu'il faut partir pour obtenir par analyse les éléments qu'il renferme" 6 (de Saussure, 1962[1916], p. 157). This principle is abundantly illustrated by Trubetzkoy (1958[1939]). Three examples from his general taxonomy of vowel systems (pp. 98-99) are shown in Figure 2.

\footnotetext{
6 "It is from the coherent totality that one has to start in order to reach, by analysis, the elements it contains."
} 
E. Itkonen

A

$\begin{array}{cccccc}\text { i } & & & & \text { u } \\ & & \text { a } & & \\ & & & & \\ & & & & & \\ \text { i } & & & & \text { u } \\ & \text { e } & & & \text { o } & \\ & & \text { a } & & \\ & & & & \\ & & & & \\ \text { i } & & & & & \\ \text { e } & & & & \text { u } \\ \text { ä } & & & & & \text { a }\end{array}$

Figure 2. A: "two-level triangle system" (zweistufiges Dreiecksystem)

B: "three-level triangle system" (dreistufiges Dreiecksystem)

C: "three-level square system" (dreistufiges Vierecksystem)

The où tout se tient principle teaches two lessons concerning A-C. First, the roles of (e.g.) /a/ are different in A, B, and C. Second, the role of (e.g.) /a/ is the same in all languages that exemplify (e.g.) the system A and thus qualify as analogous in this respect.

The primary use of the structuralist où tout se tient principle belongs to the paradigmatic context, but it can easily be extended to syntagmatic contexts such as (16) and (17). It must be carefully distinguished from the "whole $>$ parts" thesis, which admits a number of more or less adequate interpretations.

\subsection{2 "Parts do not exist outside of wholes"}

A rather extravagant interpretation of the "whole > parts" thesis states: "The parts ... do not have an independent existence outside of the whole construction ..." (Croft, 2001, p. 48). Taken literally, this is just false. All the words (= lexical units) that occur in the constructions (16) and (17) have an "independent existence" in English dictionaries, hence "outside of" (16) and (17). Even the suffix $-s$ has an "independent existence" in any grammar of English, hence "outside of" (16). Therefore, something else must be meant. But what is it? As far as I can see, one of two things is being asserted here, each in a misleading way. First, if $x$ is a member of a list $\{x, y, z\}$, it certainly exists, but in a way that is totally different from how it exists as part of the structure $\langle x, y, z\rangle$, which just repeats the opposition between (1) and (2). Second, the way that $x$ exists as part of a given structure $\langle x, y, z\rangle$ is never exactly the same as when it exists as part of any other structure $\langle x, y\rangle,\langle y, x, z\rangle,\langle x, y, z, w\rangle$, etc.

What is being claimed here reduces to a tautology: the way that $x$ exists in $\langle x, y, z\rangle$ cannot be (exactly) repeated outside of $\langle x, y, z\rangle$. But remember that it is often debatable whether we have $\{x, y, z\}$ or $\langle x, y, z\rangle$. In principle, the way that one coin exists as part of group of three coins is not exactly the same as the way it exists as parts of a group of four coins or, for that matter, of three coins and one pencil, etc. But this just repeats the fallacy that all conceivable properties/relations are (equally) relevant ones (again, Phillips 1976, pp. 9-10). 
Still, this issue contains a rational kernel. In India some 1500 years ago there was a lengthy debate concerning the primacy of word vs. sentence. Both sides of the debate accepted the dictum padaprakrtih samhita (where pada $=$ word, prakrtih $=$ origin, samphit $\bar{a}=$ sentence), but one side understood it as a determinative compound ('sentence is the origin of words'), whereas the other side understood it as a possessive-exocentric compound ('sentence is that which has words as its origin') (Itkonen, 1991, p. 82; Houben, 1997, pp. 116-118). Obviously, each side has its own justification. While particular tones/words would not exist if there were no melodies/sentences, they can nevertheless be identified independently of their occurrence in any particular melody/sentence, as noted by Nagel (1961, p. 399).

Moreover, it is certainly true that the parts of a discontinuous whole cannot be identified independently from each other. Let us consider the Swedish expression for the combination of 'definite' and 'singular', exemplified by det stor-a hus-et ('the big house'). Both det and - $a$ also occur outside of this construction, but in other functions, i.e. det as a demonstrative pronoun ('it' 'that'), e.g. in Det var bra! ('That was good!'), and $-a$ as an exponent of 'plural' in adjectives, e.g. Här finns ing-a stor-a hus- $\phi$ ('There are no big houses here', where also $-\phi=$ PL). Hence the identity of det _ $a \_$_t is indeed determined by the whole which they are part of. (To be sure, hus-et ['the house'] occurs in the same function also outside of this construction.) But it is not true that all wholes can be regarded as discontinuous in this (strong) sense.

\subsection{3 “Atomic $\neq$ primitive”?}

Within (most varieties of) Construction Grammar, constructions are wholes, and their theoretical novelty vis-à-vis such traditional notions as "pattern" or "structure" presumably consists in that they cannot be reduced to their atomic parts: "Constructions, not categories and relations, are the basic, primitive units of syntactic representation. The categories and relations internal to constructions are derived from them ..." (Croft, 2001, p. 48; emphasis added). By contrast, "atomic units are those that cannot be broken into smaller parts in the theory" (p. 47; original emphasis). Notice that "the internal structures of words are also constructions" (p. 17).

In order to test the validity of the atomic vs. primitive distinction, we can make use of our Yoruba examples in (14) and (15). We have seen that the constructional difference between verbs and nouns is fully accounted for in terms of three features (= "categories and relations"), namely: (i) quality (= consonant vs. vowel), (ii) order (= before vs. after), (iii) number (= 2 vs. 3 or 5). Should (i)-(iii) be called "atomic" or "primitive"? This is a meaningless question. The important thing is that after (i)-(iii) have been applied, there remains nothing to describe, certainly no "emergent" property uniquely possessed by the "construction itself". In particular, it is certainly not the case that such general categories and relations as quality, order, and number could somehow be "derived" from the (allegedly "more primitive") (14) and (15).

By the same token, these categories and relations certainly have "an independent existence outside of" the constructions they describe, for instance, outside of verbs like $p a$ and nouns like apá. If regarded as (maximally general) "parts", they constitute the refutation par excellence of what is claimed in the titles of the previous two subsections.

\section{Relevance of "parts and whole" for central linguistic phenomena}

With the conceptual and interpretative issues discussed in the previous section, we can now address in some more detail a few central topics in linguistics, where the issue of "parts and whole" is particularly relevant. 
E. Itkonen

\subsection{Compositionality and "one meaning - one form"}

"The meaning which subsists in each word is, in a sense, the minimal unit of the sentence, ... so, in turn, the structural combining of meanings will produce sentences by combining words" (Apollonius Dyscolus / Householder, 1981, p. 19). This general principle, known today as compositionality, is a necessary ingredient of every linguistic theory: "Some degree of compositionality must obviously be assumed. ... we will concentrate on semantic compositionality" (Langacker, 1987, pp. 448-449; emphasis added). "Linguists agree, and so does the average lay person, that the reason The cat stole the hat means something different from The cat ate the hat is that stole and ate make different contributions to the interpretation of the whole, ... (Sweetser, 1999, p. 133). "We parcel out the responsibility for meaning among the various elements of the sentence" (Goldberg, 2006, p. 224; emphasis added).

Example (13) from Section 3.1 is an example of formal compositionality. It illustrates "whole = parts" because $S$ is the sum of $N-1$ and $N-2$, as defined by Nagel (1961). The linguists quoted in the previous paragraph, by contrast, are speaking about semantic compositionality. Otherwise, the basic idea seems to be the same: "In fully compositional expressions, the composite structure $[\mathrm{C}]$ is computable in this sense, hence $[C]=[A B] \ldots:[C]$ is a regular compositional function of $[\mathrm{A}]$ and $[\mathrm{B}]$ " (Langacker, 1987, p. 450; original emphasis).

This claim certainly illustrates 'whole = parts', but not exactly in the sense of (13). Why not? Because, assuming that we are dealing with mathematical functions, $[C]$ is the value of a function applied to the arguments [A] and [B], not the function itself. (If it is the function, what is the value?)

It is generally agreed today that, on closer analysis, semantic non-compositionality - and correspondingly, the lack of "fully compositional expressions" - is quite widespread, and certainly more so than was thought to be the case some 40 years ago. The examples typically adduced in support of this position are provided by combinations of lexical meanings, i.e. by such expressions as black bird, fake gun, and roasted meat, examined in Langacker (1987), Sweetser (1999), and Croft (2001), respectively. Yet the (non-)compositional nature of grammatical meanings has also been noticed, as shown by such examples as comput-er and deriv-ation-al, examined by Langacker (1987) and Goldberg (2006), respectively.

For the present purpose, the most interesting type of example is one "in which a composite structure has substantial semantic content not attributable to either component" (Langacker, 1987, p. 452; also p. 292). For instance, in Eastern Mono, combining an intransitive verb with a prima facie instrumental prefix produces a causative meaning. Examples like this open the way to considering, more generally, how grammatical meanings are expressed. In his analysis of Eastern Mono Langacker still takes it for granted that grammatical meanings must have some formal exponents (or "components"), e.g. prefixes. But taking into account those near-ubiquitous cases where grammatical meanings have zero expression, or are not expressed at all, opens up an entirely new perspective on the "whole vs. parts" discussion, as discussed in Section 4.2 below.

At this point, we have reached the conclusion that compositionality equals "whole $=$ parts" whereas non-compositionality equals "whole $\neq$ parts". In order to move ahead, some additional apparatus is needed. Consider the following two citations: 
Public Journal of Semiotics 7 (2)

Jede Sprache ist unaufhörlich damit beschäftigt ... für das funktionell Gleiche auch den gleichen Ausdruck zu schaffen. ... Trotz allen Umgestaltungen, die auf dieses Ziel losarbeiten, bleibt es ewig unerreichbar“ (Paul, 1975[1880], p. 227).?

In an ideal language, ... the same modification of sounds would always have the same meaning, and the same signification or function would always be expressed in the same formal way. ... [But w] e must never lose sight of the fact that one form may have two or more significations, or no signification at all, and that one and the same signification or function may be denoted now by this and now by that formal means, and sometimes by no form at all (Jespersen, 1965[1924], p. 41; emphasis added).

What Paul and Jespersen are grappling with here has been called the principle of "one meaning - one form" (Anttila, 1989[1972], p. 101), or the 1M1F principle, for short. More precisely, it denotes a one-to-one correspondence between meanings and forms: 1M1F, 2M2F, 3M3F, etc. Plank (1999) has coined the following terms for the different $1 \mathrm{M} 1 \mathrm{~F}$ options, both syntagmatically and paradigmatically:

- $\mathrm{S}$ (yntagmatic) $\quad 1 \mathrm{M} ? \mathrm{~F}=$ separative (one meaning, any number of forms)

?M1F = local (any number of meanings, one form)

- $\mathrm{P}$ (aradigmatic) $1 \mathrm{M} ? \mathrm{~F}=$ distinct $($ one meaning, any number of forms)

$? \mathrm{M} 1 \mathrm{~F}=$ invariant (any number of meanings, one form)

The ideal types are $\mathrm{S}-1 \mathrm{M} 1 \mathrm{~F}=$ separative and local (syntagmatically) vs. $\mathrm{P}-1 \mathrm{M} 1 \mathrm{~F}=$ distinct and invariant (paradigmatically). The deviations from $1 \mathrm{M} 1 \mathrm{~F}$, i.e. non-1M1F, both in the syntagmatic (= S) and in the paradigmatic $(=\mathrm{P})$ dimension, are summarized as follows:

- $\quad \mathrm{S} \quad 2 \mathrm{M} 1 \mathrm{~F}=$ cumulative (and local)

$1 \mathrm{M} 2 \mathrm{~F}=$ (separative and $)$ discontinuous

- $\quad \mathrm{P} \quad 2 \mathrm{M} 1 \mathrm{~F}=$ ambiguous (and invariant)

$1 \mathrm{M} 2 \mathrm{~F}=($ distinct and $)$ variant

Notice the following generalization: $1 M 2 \mathrm{~F}$ means here 'one meaning - at least two forms' while $2 M 1 F$ means 'at least two meanings - one form'. These are the basic (or default) types of non-1M1F. In practice, not only local but also discontinuous units can be cumulative, just as not only invariant but also variant units can be ambiguous. ${ }^{8}$

The $1 \mathrm{M} 1 \mathrm{~F}$ principle is of considerable interest, but we shall make only a limited use of it in what follows. First, we shall concentrate on syntagmatic wholes and their "pre-syntagmatic" (rather than paradigmatic) parts. Second, the (syntagmatic) distinctions 'separative vs. cumulative' and 'local vs. discontinuous' prove to be unimportant because they are not needed to differentiate between wholes and parts.

As noted in the previous sub-section, compositionality is about "predicting" the whole from its parts. In the absence of mathematical functions, this idea is bound to

\footnotetext{
7 "Each language is constantly trying ... to create the same expression for what is functionally the same. ... In spite of all reorganizations made in order to achieve this goal, it remains forever unattainable."

${ }^{8}$ Instead of 'discontinuous' and 'ambiguous', Plank (1999) uses the terms 'extended' and 'homonymous', respectively. Notice the following equivalences: 'cumulative' = 'portmanteau' and 'variant' = 'allomorphic'/ 'synonymous' / 'flexive'.
} 
remain vague. The use of the $1 \mathrm{M} 1 \mathrm{~F}$ principle may bring some clarification. Let us consider how the 'horizontal vs. vertical surface' distinction is expressed in (18) and (19).

(18) The picture is on the table.

(19) The picture is on the wall.

In this particular instance the analysis is exceptionally easy because (18) and (19) are identical apart from the table vs. wall contrast. Therefore (assuming the normal or default reading for both sentences) the horizontal vs. vertical distinction must be expressed by the semantic difference between these two words. In both cases we have S-1M1F, more precisely: 'horizontal' = table in (18) and 'vertical' $=$ wall in (19).

Next, let us consider the German counterparts of (18-19), given in (20-21).

$\begin{array}{lllll}\text { Das Gemälde } & \text { lieg-t } & \text { auf } & \text { dem } & \text { Tisch. } \\ \text { DEF picture } & \text { lie-PRS.3P.SG } & \text { on } & \text { DEF.DAT.SG.M/N } & \text { table } \\ \text { Das Gemälde } & \text { häng-t } & \text { an } & \text { der } & \text { wand } \\ \text { DEF picture } & \text { hang-PRS.3P.SG on } & \text { DEF.DAT.SG.F } & \text { wall }\end{array}$

Now, clearly, the horizontal vs. vertical distinction is expressed by the prepositions auf vs. an. But since the semantic difference between Tisch and Wand is exactly the same as that between table and wall, the horizontal vs. vertical distinction, which in the English sentences is expressed only by table vs. wall, must in the German sentences be also expressed by Tisch vs. Wand, even if "secondarily". Moreover, the posture verbs liegen vs. hängen repeat the same distinction. Thus, the horizontal vs. vertical distinction is expressed here by three separate forms, which means that we have the situation S-1M3F.

Having examined one part of the whole, let us examine the whole itself, i.e. the entire sentence-meanings (18)-(21). Are they compositional or not? Both (18) and (19) consist of six words each of which contributes its own meaning to the global sentence meaning. For instance, on the table can be replaced by such variants as under the table, on this table, on the chair. Thus, (18) and (19) seem to satisfy the "building-block metaphor", which underlies the very idea of compositionality (Langacker, 1987, p. 452), and was already espoused by Apollonius Dyscolus.

On reflection, however, it turns out that this assessment could not have been made without a few simplifications. Any finite verb expresses several grammatical meanings, as will be shown by the discussion of (23) in the next subsection, and this is true also of such a "minimal" verb-form as is in (18) and (19). For simplicity, it may be stipulated that in this context the verb is expresses only affirmation, as opposed to the negation is not. With this qualification, we have here as good an example of "full compositionality" as possible. This is an important result. Compositionality turns out to be identical with the (syntagmatic) $1 \mathrm{M} 1 \mathrm{~F}$ principle.

Let us assume that sentences like Young men gulped down dark beer exemplify the following type of structure:

$$
[[\mathrm{AB}][\mathrm{CD}][\mathrm{EF}]]
$$

Thus, (22) is a hierarchy with three distinct levels, i.e. sentence, phrase, word. The 1M1F principle must be valid at each level, or in the top-down direction: S-1M1F (= sentence) > S-3M3F (= phrase) > S-6M6F (= word). Now it becomes clear that purely semantic compositionality is not a coherent notion. Why not? Because compositionality is identical with "one meaning - one form". It is not possible to imagine a semantically 
compositional structure where meaning has no systematic relation (or no relation tout court) to form.

Two qualifications need to be added. First, purely formal compositionality is of course a coherent notion (Section 3.1). Second, "semantic" compositionality is viable if the content of semantics is enlarged so as to encompass methods of constructing ontological structures of increasing complexity. This idea is exemplified by the "reality algebra" contained in Montague grammar, with the primitive notions $e, t$, and $s$ (= thing, truth-value, and possible world) (Itkonen, 1983, p. 142-162).

In conclusion, a basic shortcoming of the notion of compositionality needs to be addressed. Let us consider our example (6), i.e. Men drink beer. It is clear that one meaning, i.e. 'animateness', is expressed by the two forms men and drink, just as 'liquid' is expressed both by drink and beer. This result can be generalized, mutatis mutandis, to all sentences of all languages. It is normally said that the words of a sentence must be "compatible" with each other. Two words can be (semantically) compatible only if they share a common meaning, which amounts to S-1M2F. "Perfect" compositionality is therefore impossible. Saying that 'animateness' is "expressed" by men but (only) "implied" by drink does not affect this conclusion.

\subsection{Numerical measures for "whole > parts"}

In Section 2 we suggested that there is no numerical sense in which the whole $\langle x, y, z\rangle$ is more than the list of its parts or $\{x, y, z\}$. The situation needs to be re-assessed, now that we have introduced the $1 \mathrm{M} 1 \mathrm{~F}$ point of view.

\subsubsection{The argument}

At this point we may apply part of the argument that I presented in earlier work (Itkonen, 2013, pp. 31-35). Consider the Yoruba sentence in (23).

$$
\begin{aligned}
& \text { ó rí i } \\
& \text { s/he see it } \\
& \text { 'S/he saw him/her/it' }
\end{aligned}
$$

Taken as a whole, (23) is a syntagmatic entity consisting of three integrated parts, namely the words $o$, rí, and $i$ in the order exhibited by (23). As always, there must be a list which, corresponding to the whole, contains its disconnected parts. As the members of such a list, these three words are assigned the following meanings by Rowlands (1969): $r i$ = 'to see' (or 'to find') (p. 273); $o=$ '(unemphatic) subject pronoun' (p. 15); $i=$ "vowel of the verb repeated" = '(unemphatic) object pronoun' (p. 19). Thus, there are three forms and three meanings, summarized as follows:

$$
\{\text { ó, rí, V }\}=3 \mathrm{M} 3 \mathrm{~F}
$$

As members of a list (= unordered set), ó, rí, and $V$ (owel) cannot of course be syntagmatic units. (This is also why the object pronoun is presented as V, i.e. before it is assimilated to the vowel of $r i$ and dissimilated from the tone of rí.) On the other hand, they are not paradigmatic units either. From the paradigmatic point of view, the wordform rí has three meanings: 'to see'; 'to be' (in connection with phonaesthetic adjectives), as in ó rí wúruwùru ('it is untidy', p. 155); 'formerly' (i.e. ó $t i V=$ 's/he just V-ed' vs. ó $t i$ $V r i=$ 's/he used to $\mathrm{V}$ ', as in mo ti ḿmu sigá rí = 'I used to smoke cigarettes', p. 78). But only the meaning 'to see' is relevant here, because the other meanings are not 
(disconnected) parts of this whole, i.e. (23). Thus, the units of (24) should be called presyntagmatic rather than paradigmatic. (24) is secondary vis-à-vis (23). In just the same way, when an institution is conceptualized as a network of relevant social roles, it is only secondarily that these can be enumerated in a list.

If (24) has three forms and three meanings, what about (23) as a whole? This is the crucial question. The English translation already gives a rough idea of the grammatical meanings expressed by (23), but let us make this more precise. We need to exploit the general structuralist principle which says that in any system a unit is what the other units are not: "Leur plus exacte caractéristique est d'être ce que les autres ne sont pas"9 (de Saussure, 1962[1916], p 162); in other words, "omnis determinatio est negatio", as Spinoza put it. In the Yoruba context, (23) exemplifies what Keenan (1976) calls "semantically basic sentence" (= SBS). When we compare (23) with its closest neighbours, each of which has a form (minimally) more complex than (23), each comparison elicits one grammatical meaning expressed by, or contained in (23).

(25) yó rí i

(26) ó ńrí i

(27) ó bá rí i

(28) ó di rírí

(29) rírí l'ó rí i

(30) kò rí i

(31) ó rí i bi? s/he will see it

$\mathrm{s} /$ he used to see it

s/he might see it (that/if)

it was found

s/he really saw it

$\mathrm{s} /$ he did not see it

did s/he see it? future

habitual

non-factive

passive

focal

negative

question

Thus, (23) turns out to express the following grammatical meanings: (i) past, as opposed to (25); (ii) completive, as opposed to (26); (iii) factive, as opposed to (27); (iv) active, as opposed to (28); (v) non-focal, as opposed to (29); (vi) affirmative, as opposed to (30); (vii) assertion, as opposed to (31). The presence of these grammatical meanings in (23) is undeniable, perhaps apart from (v). Its inclusion can be defended, however, given the extraordinary frequency of the focal construction (here: rírí ni ó rí $i>$ rírí l'ó rí $i$ ).

In moving from (24) to (23), we move from a $\{$ list $\}$ of units to a <structure> where the units stand in a definite relation to each other; and in (23) the structure/relation is literally identical with the order of the listed units. It is not an additional formal element that should be added to the (lexical) forms contained in the list. The meaning-form ratio of (23), when all lexical and/or grammatical meanings are taken into account, is as follows, with the same number of forms, i.e. 3, as in (24).

$$
<\text { ó, rí, i> = } 10 \mathrm{M} 3 \mathrm{~F}
$$

Let us recall that, according to Nagel (1961, p. 388), it is a trivial truth that a whole like (32) is more than the list of its parts, i.e. (24). The interest of the (24) vs. (32) comparison resides in the fact that, unlike in connection with (1) vs. (2) etc, it now becomes possible to have a numerical measure that shows the exact degree to which the whole is greater than the sum of its parts. This is one way to give substance to the "whole $>$ parts" thesis, even if it may not be exactly what most of its proponents have had in mind.

In a more careful analysis, it should be said that the pronoun ó cumulatively expresses the following three meanings: 'agent/subject', 'third person', and 'singular'; and this is true, mutatis mutandis, of $i$ as well. But the important point is that the number

\footnotetext{
9 "Their characteristic property is, more precisely, to be what the others are not."
} 
of these (grammatical) meanings is the same in the list and in the sentence. Therefore, for simplicity, we may ignore here the 'separative vs. cumulative' distinction and say that each of the forms $o$ and $i$ expresses just one meaning. This is how we get the numbers $3 \mathrm{M} 3 \mathrm{~F}$ and $10 \mathrm{M} 3 \mathrm{~F}$ for $\{o, r i, i\}$ and $\langle o, r i, i\rangle$, respectively.

This result can be generalized in an obvious way to examples (5) and (6) in Section 2.3. The list (5) \{men,drink,beer $\}$ contains three (lexical) forms and three lexical meanings; the meaning of drink is an abstraction roughly comparable to V(owel) in (24): it becomes definite only in the sentence context. There are also two grammatical meanings involved, namely PL (of men) and SG (of beer), but they can be ignored. Because they are just repeated in the sentence (6) <men,drink,beer>, they contribute nothing to differentiating between the list and the sentence. Because the list enumerates the parts of the sentence (i.e. of "the whole"), it is true by definition that the list and the sentence(-structure) contain the same number of parts, i.e. lexical or grammatical forms, with only the difference that they are disconnected in the list and integrated in the sentence. Just as in connection with (23), the interest lies in those meanings which are contained in the structure but not in the list. As for (6), which comes close to exemplifying the semantically basic sentence (SBS) in English, these new meanings include at least the following: present, factive, active, affirmative, assertion.

$$
\{\text { men, drink, beer }\}=3 \mathrm{M} 3 \mathrm{~F}
$$

$$
<\text { men, drink, beer }>=8 \mathrm{M} 3 \mathrm{~F}
$$

Again, the whole is (much) greater than the sum of its parts. A look at (5) vs. (6) and (24) vs. (32) reveals that not just the number of (formal) parts but also the number of lexical meanings is the same in the $\{$ list $\}$ and in the <sentence>. The asymmetry between the list and the sentence is due to the fact that the latter contains a greater number of grammatical meanings. And this is in turn due to the fact that, apart from (the mutual order of) the lexical forms, a lot of grammatical meanings are expressed by zero: it is enough that words are just put together to form a sentence. (To be sure, there are rare cases where lexical meanings too are expressed by zero; cf. (42) and (43) below.) It follows that, as the number of overt (and meaningful) grammatical forms increases, the list vs. sentence asymmetry is likely to decrease. Still, it never disappears entirely. Measured by the number of meanings expressed, the whole sentence will always be greater than the sum (= list) of its parts. The same may not be true of all sub-sentential wholes, as discussed in Subsection 4.4.2 below.

A look at (32) reveals that we are dealing with cumulation: 'syntagmatically, more meanings than forms'. Customarily, cumulation is taken to be a property of morphemes (cf. Velupillai, 2012, p. 104), but here we have an instance of sentence-level cumulation. Let us repeat that, with respect to word lists like (24) and (5), "disconnected" is replaced by "pre-syntagmatic", whereas with respect to sentences like (32) and (6), "integrated" is replaced by "syntagmatic". The mutual relation of pre-syntagmatic and syntagmatic is concealed by orthography in the case of $o$ and $r i$ but is better illustrated by the difference between $V$ and $i$.

\subsubsection{Qualifications}

At first, it may be thought that grammatical meanings must have non-zero expressions in polysynthetic languages like West Greenlandic. However, the form of the SBS is no more complex in West Greenlandic than it is in Yoruba (33). 


\author{
taku-vaa \\ see-3SG.AG.3SG.PAT \\ 'S/he saw him/her/it.'
}

The list here is as follows: $\{t a k u-,-v a a\}=3 M 2 F$. That is, the (polysynthetic) sentence (33) is formally even less complex than the (isolating) sentence (23), given that it has only two forms: whatever its etymology, the suffix - vaa, which expresses the AG/PAT relation and thus corresponds to $o-i$, exemplifies from the synchronic point of view cumulation, or S-2M1F. (This fact is relevant for the ó rí $i$ vs. taku-vaa contrast, even if it is not relevant for the $\{t a k u-,-v a a\}$ vs. $\langle t a k u-,-v a a\rangle$ contrast.) The precise number of the new grammatical meanings in the structure $\langle t a k u-v a a\rangle$ must be determined in the same contrastive way (applied to West Greenlandic data) as it was done by means of (25-31) in connection with (32).

In general, the exact status of zero-expression has been poorly understood. According to Croft (2003, p. 103), for instance, the English sentence This car- $\phi$ run-s expresses the following grammatical meanings: DEM.SG $(=$ this $)$, SG $(=-\varnothing)$, 3.SG.PRS $(-s)$. But this is far from sufficient. Surely at least the following meanings, expressed also by (6), (23), and (33), must be added: factive, active, affirmative, assertion. We encounter here "the blind spot of current typological linguistics", to repeat the title of previous paper (Itkonen, 2011c). A few corrections, long overdue, have been offered in Itkonen (2013).

The argument was presented here in the simplest possible form, namely by using SBS's, and more precisely such SBS's where there is no doubt about word-boundaries, as in (6) and (23), or about the lexical vs. grammatical boundary, as in (33). (It is immaterial that $\delta$ and $i$ might equally well, or even better, be regarded as affixes rather than fullfletched words.) When the amount of grammatical forms increases, there will inevitably be disputes about the proper way of segmentation. But none of this needs to concern us here.

\title{
4.2.3 Implications
}

Apart from rare exceptions, the numerical measure is given by the number of grammatical (and not lexical) meanings. Therefore the "whole vs. parts" perspective has revealed a definite asymmetry between lexical and grammatical meanings. It would remain hidden if the existence of the lexical vs. grammatical distinction is denied a priori, in the spirit of the following statements: "There is no meaningful distinction between grammar and lexicon" (Langacker, 1987, p. 3). "I do not believe that ... the distinction between grammar and lexicon ... can ultimately be maintained" (p. 449). Croft (2001, p. 17) agrees: "Thus, there is a continuum between the lexicon and syntactic constructions. ... [T] he internal structure of words are also constructions. ... In other words, construction grammar has generalized the notion of a construction to apply to any grammatical structure, including both its form and its meaning. ... (compare Langacker, 1987, pp. 25-27, 35-36).”

If there is a continuum between grammar and lexicon, the distinction between the two is gradual, not absolute. But it is just a mistake to think that gradual distinctions are no ("meaningful") distinctions at all (Itkonen, 2016). Let us add one more example: Because there is no definite boundary between dictionary and encyclopedia, it is inferred that all meanings are encyclopaedic. The underlying fallacy was exposed already by Pap (1958, p. 401): "But to deny a distinction because of its vagueness is, of course, a semantic naiveté of the first order". Or to put it even more eloquently: "the existence of pink does not undermine the distinction between red and white, and dawn does not 
indicate that day and night are really [or "ultimately"] the same" (Paulos, 1988, p. 63). In an everyday context it is easy to understand that gradual distinctions are meaningful (just think of day vs. night or rich vs. poor), but comparable understanding becomes nearly impossible in an esoteric context like theoretical linguistics.

\subsubsection{Summary}

The phenomenon exemplified by (23) is thoroughly familiar. And yet, if viewed from some distance, as it were, it looks almost miraculous. The list of the parts is quite unimpressive: two vowels $(=\sigma, i)$ and one syllable $(=r i)$, with just three meanings of their own. But when they are put together, a very complex whole of ten meanings literally emerges, as if by some sort of l'alchimie du verbe. The idea of emergence is indeed fully justified here, in the sense of "more". (Let us recall that water, qua emergent, is certainly different from, but not more than, hydrogen-cum-oxygen.) On reflection, of course, this type of emergence can be explained down to its last detail; and the explanation is provided by the notion of basic use (exemplified by the SBS's). What people communicate most often must be given the shortest expression. Thus, the example (23) reveals the ultimate rationality of speakers, as sedimented in language, and by the same token, the essence of (linguistic) functionalism (Itkonen, 2013).

What Whitney (1979[1875], p. 238) says about the entire Chinese language, is just as true about the SBS's of particular languages, like (6), (23), and (33):

\footnotetext{
Language is only an instrumentality, and the mind the force that uses it; ...the mind, which in all its employment of speech implies a great deal more than it expresses, is able to do a high quality of work with only the scantiest hints of expression, catching from the connection and from position the shades of meaning and the modes of relation which it needs.
}

Let us accept structure as a superordinate notion which, in the spirit of the previous paragraph, subsumes both "language" and "sentence". The gist of Section 4.2 may then be summarized as follows: "That [structure] ranks highest which goes furthest in the art of accomplishing much with little means, or, in other words, which is able to express the greatest amount of meaning with the simplest mechanism" (Jespersen, 1922, p. 324).

\section{3 "One meaning - one form" as a dogma: monoexponentialism}

"The universal default is to express each category by a dedicated formative. These are monoexponential (or separative) formatives. Polyexponential (or cumulative) formatives, i.e. formatives which simultaneously code more than one category, are much rarer" (Bickel and Nichols, 2005, p. 90). These statements are contradicted by the argument in the preceding subsection. The "categories coded on the verb" are said (ibid, p. 94) to include the following: agreement (= AG/PAT person), tense, mood, voice, polarity, illocution (= speech act). If the monoexponentialist thesis were true, "the universal default" would be for all verbs of all languages to have (at least) six separative formatives, in addition to the lexical root/stem. Anyone who has even casually glanced at any natural language knows this to be false. For instance, apart from AG/PAT persons, none of these (or any other) categories is expressed by dedicated formatives in (6), (23), or (33), which qua SBS's represent the most frequent sentence types of the respective languages.

So how is it possible to deny the existence of ubiquitous cumulation? It is simply defined out of existence. If many tense/aspect/mood (= TAM) categories are 
(cumulatively) expressed by a single formative, they are counted as one category, "thereby avoiding difficult decisions as to whether something is aspect or tense or mood" (ibid, p. 95); and the same goes for formatives cumulatively expressing TAM and illocution (as well as affirmative polarity). Thus, whether S-2M1F remains a possible option, depends on the whim of the analyst. Although empirically true, it is ruled out whenever it is felt to be "difficult".

S-1M2F is disposed of in the same way: One category is counted as many if it is expressed discontinuously: when one category is simultaneously expressed at several places (in the verb), "we counted the category twice (or more)" (ibid, p. 95). Hence, S$1 \mathrm{M} 2 \mathrm{~F}$, although present in practically all languages, is made to disappear at will.

The same claims are repeated by Velupillai (2012): "It is much more common for languages to have separative morphemes than cumulative. In Bickel and Nichols' (2011) database 127 languages (or 79.4\%) have separative markers for tense/mood/aspect, while $29(18.1 \%)$ have cumulative markers ..." (p. 106).

After these strongly negative remarks, it is only fair to mention the type of data which at least approximates the ideal of monoexponentialism. Logically enough, it must be the opposite of SBS's, and especially in a language like Turkish. Consider the sentence in (34), suggested Whitney (1979[1875], p. 233). But notice that even this fine example of (almost) 1M1F has no exponents for 'assertion' and 'affirmative'. ${ }^{10}$

sev-ish-dir-il-e-mi-yor-du-k

love-RECP-CAUS-PASS- 'cannot'-NEG-CONT-PST-1PL

'We were not being capable of being made to love each other.'

\subsection{The case for "whole < parts"}

The examples (6), (23), and (33), which justify "whole $>$ (list of) parts", illustrate the general notion that there are more meanings in the structure than in the list. By the same token, "whole < parts" ought to be justified when there are fewer meanings in the structure than in the list.

\subsubsection{Idioms}

If we disregard the grammatical meanings, the sentence John drank beer has as many lexical forms and meanings as the corresponding list, namely three: $\{3 \mathrm{M} 3 \mathrm{~F}\}=\langle 3 \mathrm{M} 3 \mathrm{~F}\rangle$. This is why it qualifies as (lexical-)compositional. By common consent, idioms are noncompositional and thus deviate from S-1M1F. Let us consider Croft's (2001) favourite idiom, namely to kick the bucket (p. 26, 56), as in the sentence John kicked the bucket. The corresponding list has three lexical forms and meanings whereas the sentence has the same number of lexical forms but only two lexical meanings, namely 'John' and 'died', the latter being idiomatic.

(35) $\{$ John, kicked, the bucket $\}=3 \mathrm{M} 3 \mathrm{~F}$ vs. $<\mathrm{John}$, kicked, the bucket $>=2 \mathrm{M} 3 \mathrm{~F}$

It has been maintained that because idiomatic meanings are non-predictable or emergent, they support the "whole $>$ parts" position. This is a mistake. They certainly support the "whole $\neq$ parts' position, but - as we just saw - here the whole is less than the

\footnotetext{
${ }^{10}$ The notion of monoexponentialism is scrutinized at length by Itkonen \& Pajunen (2011, pp. 105-112), and more succinctly by Itkonen (2013, pp. 36-37).
} 
sum of its parts.

\subsubsection{Agreement}

The principle "Whole < parts" is also exemplified by the notion of repetition or agreement. We have already seen incidental exemplifications of this general idea: 'horizontal /vertical surface' is expressed three times in the German sentences (20) and (21) while the meaning 'singular' is expressed by three distinct forms in the sentence This car- $\phi$ run-s. A more transparent example is provided by the Finnish ADJ + N agreement:

$\begin{array}{lll}\text { iso-i-ssa } & \text { punais-i-ssa } & \text { talo-i-ssa } \\ \text { big-PL-INESS } & \text { red-PL-INESS } & \text { house-PL-INESS } \\ \text { 'in (the) big red houses' } & & \end{array}$

Each of the three words in (36) has 3 forms and 3 meanings. Hence the corresponding \{list\} contains 9 forms and 9 meanings (i.e. 3 lexical and 6 grammatical meanings): 9M9F. The <structure>, i.e. the corresponding noun phrase, contains 3 lexical meanings (= 'big', 'red', 'house') but only 2 grammatical meanings (PL, INESS): 5M9F. That is, the noun phrase, taken as a whole, has just the two grammatical meanings 'plural' and 'inessive', not three exemplifications of each. It follows that the whole is indeed nonadditive, but not in the standard sense in which the whole is more than the sum of its parts, but in the non-standard sense in which it is less. Thus, ignoring PL and concentrating on the meaning INESS (plus its expressions), we get:

$$
\{\text { INESS, INESS, INESS }\}=3 \mathrm{M} 3 \mathrm{~F} \text { vs. }\langle\text { INESS }>=1 \mathrm{M} 3 \mathrm{~F}
$$

It may be objected that while in (36) each of the two grammatical meanings PL and INESS is expressed by three distinct forms (i.e. three exemplifications of $-i$ - and $-s s a$, respectively), these are token-distinct but type-identical, and therefore really just one form. The reply is that agreement between units belonging to different declensions obtains also between type-distinct forms, as in the Latin ingeni-um mobil-e ("characterNOM.SG.N versatile-NOM.SG.N' = 'versatile character'): 1M2F.

The Swahili sentence in (38) exemplifies both $\mathrm{N}+$ ADJ agreement and $\mathrm{N}+\mathrm{V}$ agreement.

$$
\begin{array}{lll}
\text { vi-su } & \text { vi-dogo } & \text { vi-li-tosha } \\
\text { PL-knife } & \text { PL-small } & \text { PL-PST-suffice }
\end{array}
$$

'The small knives were enough.'

First, the NP has two parts, namely $v i$-su $(=\mathrm{N})$ and vi-dogo $(=\mathrm{ADJ})$, each of which contains the meaning PL (plus CLF); thus, in the list $\{v i-s u, v i-\operatorname{dogo}\}$ the sum of the PL meanings is 2 . By contrast, the NP $\langle v i-s u$, vi-dogo $\rangle$, taken as a whole, has only one PL; and $1<2$. Second, the sentence (38) has two parts, namely vi-su vi-dogo (= NP) and vi-litosha $(=\mathrm{V}$, or VP), each of which contains one PL; thus, in the corresponding list $\{N P, V\}$ the sum of meanings is 2 . By contrast, the sentence (38), taken as a whole, has only one PL. Again, 1 ("whole") < 2 ("the sum of the parts").

In anticipation of (43), let us add one more example of agreement. In Wari', there is the following contrast: mao na ('s/he went') vs. mama nana ('they went'), which means that the (semantic) SG vs. PL distinction is expressed twice (PL being expressed by means of reduplication), namely both in the verb and in the subject clitic. (More 
precisely, the clitics $n a$ and nana cumulatively express both subject person and tense/modality.)

As suggested by (23) and (25)-(31), entire sentences tend to exemplify "whole > parts" rather than "whole < parts". Still, it is interesting to learn that sentences may contain $s u b$-wholes with the latter characteristic, as shown by the NP's in (35) and (37). Just as interestingly, the same is true of entire sentences, if considered from one definite point of view such as agreement, as shown by (38). Notice that here too, the list and the structure contain the same number of lexical meanings, but different numbers of grammatical meanings. Again, we see a confirmation of the lexical vs. grammatical asymmetry, but in a sense opposite to the asymmetry revealed by contrast between examples (24) and (32).

Finally, it may be remembered that examples (6-7) in Section 2.3 show that there is an analogy between a sentence and an institution insofar as they both exemplify "whole $>$ parts". This type of analogizing can be pushed even farther. As far as "whole < parts" is concerned, it is possible to see agreement as analogous to collective behaviour where a group of persons, momentarily united and motivated by a common goal, acts like a single person.

\subsubsection{Perceptual gestalt revisited}

The foregoing does not yet exhaust the scope of "whole < parts". Lakoff (1987) makes the following suggestion: "grammatical constructions may constitute gestalts, where the whole is conceptually simpler than the sum of the parts" (p. 486-487; emphasis added). "[T]he entire ICM [idealized cognitive model] is understood as being psychologically simpler than its parts - hence the term gestalt" (pp. 489-490). This is an interesting reversal of the standard non-reductionist view.

In order to understand Lakoff's claim, we must look anew at the perceptual process depicted by (9) vs. (10), concentrating, in particular, on the output (10). On reflection, it has two slightly (but importantly) different readings, depending on the exact time-point. A distinction has to be made between the perceived whole $\mathrm{C}$ and the (perceived-cum)analyzed whole (A' + D' + B'). Once we have learned to perceive a familiar phenomenon as a gestalt, this is indeed simpler than the sum of its parts; thus, at $\mathrm{t}-1 \mathrm{:} \mathrm{C}=$ $1<\left(\mathrm{A}^{\prime}+\mathrm{D}^{\prime}+\mathrm{B}^{\prime}\right)=3$. But this learning process can always be reversed, and in theoretical analysis it must be; thus, at $\mathrm{t}-2: \mathrm{C}=\left(\mathrm{A}^{\prime}+\mathrm{D}^{\prime}+\mathrm{B}^{\prime}\right)=3 .^{11}$

Lakoff's (1987) position may be generalized, but also trivialized, as follows: if $\mathrm{C}=$ $\left(\mathrm{A}^{\prime}+\mathrm{D}^{\prime}+\mathrm{B}\right.$ '), then there is one whole and three parts; and $1<3$. Thus, the (perceptual) whole is by definition less than the sum of its parts. On this interpretation, the whole must be non-reductionist, because what is less cannot be reduced to what is more. Notice that this argument does not concern at all the physical parts A and B given in (9).

Let us conclude this subsection with a historical remark. In connection with (9) vs. (10), we saw that, roughly speaking, the perceptual mechanism creates something which, to begin with, was not there. At a more abstract level, however, perception certainly involves deleting something which was there. On perceiving a chair, for instance, the output is very much less than the input, i.e. the concrete chair. Aristotle conceptualized this situation by means of his "form vs. matter" distinction: things have both, i.e. they are "formed matter"; but when they are perceived, what the mind receives is only their forms, just as a piece of wax receives the impression of a golden signet-ring but without the gold

\footnotetext{
${ }^{11}$ Notice, incidentally, that the 'perceived vs. analyzed' distinction is not the same as Langacker's (1987, Chap. 12) distinction between compositionality and analyzability.
} 
Public Journal of Semiotics 7 (2)

(De Anima, Book II, Chapter 12).

\section{5 'Whole > parts' and normativity}

On the basis of the argument presented so far, we may agree that in English there is a whole which has the following parts: men, drink, and beer. They occur in the SVO order exemplified by (6). But they could, in principle, occur in the VSO order exemplified by (39).

\section{*Drink men beer}

What is the force which brings about (6) rather than (39)? In answering this question, let us take our cue from Jackendoff (1994, pp. 49-50). As he sees it, a sentence like *Amy nine ate peanuts is "not a possible sentence of English". But this cannot be right. Not only is it a possible sentence, but it is also an actual one, as we can verify by looking at one of its utterances that occurs in space and time, namely on this very page. More precisely, it is an actual incorrect sentence. This is what Jackendoff tries to say, but does not quite succeed: while (in)correctness is the basic normative notion, he rejects normativity within his framework. Once we open our eyes, we can clearly see that the "tie" that binds the parts together is provided by one of the norms of the English language.

This issue has been discussed in an illuminating way within the Arab linguistic tradition (Itkonen, 1991, pp. 132-134, 150-151). In Classical Arabic, the basic sentence structure is VSO, and just as causes precede their effects, so $V$ is thought to cause $S$ and $O$ to be in nominative and accusative, respectively; and in the PREP $+N$ construction it is $P R E P$ which is thought to cause $N$ to be in genitive. It was clearly realized, however, that this is 'causation' only in a metaphorical sense:

Therefore at the level of language there can be at most some sort of 'quasi-causality': it ought to be that within a sentence [the verb] is followed by [N-NOM]. By contrast, there is genuine causality at the level of the speaker. He has internalized the (social) norm concerning the nominative ending, and this (psychological) internalization, combined with the occurrence of a relevant speech intention, causes him to add the nominative ending after [N-] when [the verb] precedes. (Itkonen 1991, p. 150)

De Saussure (1962[1916]) captures the normative character of linguistic wholes with the aid of the following analogy: "Sous ce rapport on peut comparer la langue à une symphonie, dont la réalité est indépendante de la la manière dont on l'exécute: les fautes que peuvent commetre les musiciens qui la jouent ne compromettent nullement cette réalité" 12 (p. 36 ; emphasis added). When combined with the view that "la langue est une institution sociale" (p. 33), this quotation neatly summarizes the content of Subsections 2.3-2.5. The very essence of normativity is expressed in the remark that incorrect (results of) actions, like (39), neither refute the existence of a norm nor falsify the corresponding norm-formulaton. Why? Because these are about correct (results of) actions, like (6) (Itkonen, 1978, pp. 156-168, 2003, pp. 15-21).

There is a certain sense in which normative entities are more than their either physical or perceptual "substrata". A sentence like (6) is experienced quite differently by those who know English and by those who do not; and the latter must fail to grasp the

\footnotetext{
12 "In this respect we can compare language to a symphony insofar as the reality of the latter is independent of the way it is performed: this reality is not thwarted by mistakes committed by the musicians who play it."
} 
crucial difference between (6) and (39). The basis of this difference is explained as follows: "But the correctness of a performance is not among its perceptual characteristics: it cannot be because it is a relation between the performance and an adopted rule [or norm] - a relation which is more fully expressed by the statement that the performance conforms to the adopted rule" (Körner, 1960, p. 117; emphasis added).

\section{6 "Whole > parts" and predictability}

"In T[ransformational] $\mathrm{G}$ [rammar] it is customarily said that a grammar explains a sentence by generating it. In this context the terms 'explain', 'predict', 'produce', 'deduce', 'generate', etc. are used synonymously" (Itkonen, 1978, p. 239). It is in the same rather diffuse sense that within grammatical description the whole is claimed to be, or not to be, "predicted" from its parts. Just as well it could be said that an axiomatic theory either "predicts" its theorems or fails to do so. This is not the standard sense in which 'prediction' is used in philosophy (of science) (ibid, pp. 4-9).

If we want to have genuine predictions, we must look elsewhere. In each language, the SBS is the formally minimal sentence, i.e. the closest approximation to zeroexpression and therefore the best example of "whole > parts" (as defined in Section 4.2). What are its properties? This can be predicted fairly accurately. The SBS typically expresses those grammatical meanings that are expressed by (23): 'assertion', 'affirmative', 'active', 'factive', 'past' (or 'present'). Of course, the 'active' meaning exists only where it is in contrast with such meanings as 'passive', 'causative', 'applicative', or 'antipassive'. Moreover, if 'agent' and/or 'patient' is expressed by zero, it is typically ' $3 \mathrm{SG}$ '.

One must be prepared for (unpredictable) exceptions, as always in cross-linguistic research. For instance, in Pitta-Pitta it is the future, and not past or present, which is expressed by zero (Blake, 2001, p. 127).

One of the most spectacular exceptions is provided by Ancient Tamil (Lehmann, 1994, pp. 100-104). When the verb-form is an affirmative-factive declarative, it has the following structure: stem + tense + person. The corresponding negative verb-form has the following structure: stem + NEG + person. Thus, the tense exponent is replaced by the NEG exponent. Amazingly, the exponent for morphological negation is a zero in all persons except neuter 3SG \& PL. (The lexical, auxiliary, and syntactic variants of negation are ignored here.) As a result, there are contrasting verb-forms like the following:

$$
\begin{array}{lll}
\text { paat-in-aan } & \text { vs. } & \text { paat- } \varnothing \text {-aan } \\
\text { sing-PST-3SG.M } & & \text { sing-NEG-3SG.M } \\
\text { He sang } & & \text { He did/does/will not sing }
\end{array}
$$

Let it be added that, more generally, the role of zero is extraordinary in the Ancient Tamil inflection. Remarkably, both Proto-Tamil and Modern Tamil, i.e. the language stages that either preceded or followed Ancient Tamil, exhibit rich (non-zero) noun and verb inflection (for discussion, see Itkonen 2011b).

In (40) an extraordinary grammatical meaning is expressed by zero. On the other hand, it is extraordinary that any lexical meaning should be (systematically) expressed by zero. As explained by Roberts (1997), such a situation obtains in Amele (New Guinea). The basic verb structure is $V$-O-S-TAM, i.e. the verb root is followed by the exponents of Object/Patient, Subject/Agent, and Tense-Aspect-Modality. In (41), for instance, -ad-and -ei- agree with $u q a$ and meen, respectively. 
Public Journal of Semiotics 7 (2)

$$
\begin{array}{llll}
\text { Uqa } & \text { meen } & \text { eu } & \text { hel-ad-ei-a } \\
\text { 3SG } & \text { stone } & \text { DEM } & \text { throw-3PL-3SG-PST }
\end{array}
$$

'S/he threw those stones.'

Interestingly, the meaning 'to give', which is cross-linguistically expressed by a full lexical unit, is here expressed by zero:

$$
\begin{aligned}
& \text { Uqa ho eu } \varnothing \text {-it-ad-ei-a } \\
& \text { 3SG pig DEM give-1SG-3PL-3SG-PST } \\
& \text { 'S/he gave those pigs to me.' }
\end{aligned}
$$

An analogous phenomenon occurs in Wari', where the meanings 'to say' and, by extension, 'to think', are expressed just by zero. What is said or thought is expressed by a sentence followed by a clitic. If the clitic is simple, it cumulatively expresses tense/modality and the person of the one who says or thinks; and if it is complex, it also expresses the person of the one who is being talked to or thought about. If the corresponding nouns are added, the clitics agree with them. The resulting structure, "highly unusual, perhaps unique" (p. 355), is called "verbalized sentence" by Everett and Kern (1997):

$\begin{array}{lll}\text { [mao } & \text { ta' ] } & \text { na } \\ \text { go.SG } & 1 \text { SG.FUT } & \text { 3SG.PRES }\end{array}$

The bracketed sentence means 'I will go'. The literal translation of (43) is: I will go, s/he says. It is more probable, however, that we are dealing here with 'inner speech', in which case the meaning is simply 'S/he will go'. As noted by Itkonen (2005b, pp. 176-178), the entire structure could just as well be called "sentence-like verb", because a finite verb is by definition that which is followed by a person \& tense clitic like $n a(\mathrm{SG})$ or nana (PL). It follows that units which elsewhere satisfy the criteria of nouns qualify as verbs if they are followed by (e.g.) na.

\section{Summary and conclusions}

We may conclude by first pointing out that the issue of "parts and whole" is complex, and may be interpreted differently in different domains. The emergence of water out of hydrogen and oxygen is a causal/temporal process, and so is the perception of a nonexistent sound, as discussed in Sections 2.5 and 2.6. In linguistics the situation is a different one. As shown by the discussion of compositionality in Section 4.1, the temporal change does not occur in the data, but in our focusing on the data: it is only after we have the whole firmly in our focus that we can go on to ask whether or not it can be "predicted" from its parts - to use this misleading metaphor, discussed in Section 4.6. Hence, there is a stark difference between causal and non-causal analysis. Irrespective of whether or not the results achieved in the former type of research support the "whole > parts" thesis, there is no reason why they should have any bearing on the validity of this thesis in the latter type of research.

Perhaps without realizing it, all (synchronic) grammarians agree with Wittgenstein: "Our problem is not a causal but a conceptual one" (1958, p. 203). And so do, by implication, all psycholinguists, insofar as their problem is not a conceptual but a causal one. (Notice that "conceptual" is used here in the sense in which philosophical explication qualifies as conceptual analysis.) These two types of linguistic research have 
been scrutinized in my previous work (Itkonen, 1978, 1983). Their mutual relation may be summarized by saying that the former investigates what is presupposed by the latter. What we have here is a genuine difference. Linguistics is not a monolith.

To sum up: The claim "whole $(=\mathrm{X})>$ parts $(=\mathrm{Y})$ " is meaningless in those domains where the notion of "sum" does not apply at all. "X $>\mathrm{Y}$ " has only a metaphorical meaning, i.e. it is neither (clearly) true nor (clearly) false, in those domains where it cannot be determined how much $\mathrm{X}$ is greater than $\mathrm{Y}$. ("X $>\mathrm{Y}$ " should be replaced here by the less demanding claim " $\mathrm{X} \neq \mathrm{Y}$ ".) These two options are discussed in Section 2.

The claim " $\mathrm{X}>\mathrm{Y}$ " is true in linguistics (at least) if $\mathrm{X}$ is the number of the meanings expressed by a sentence $\mathrm{S}$ while $\mathrm{Y}$ is the number of the meanings separately expressed by the disconnected parts of $\mathrm{S}$. This option is discussed in Subsection 4.2.

Finally, " $\mathrm{X}>\mathrm{Y}$ " is false either if " $\mathrm{X}=\mathrm{Y}$ " or if " $\mathrm{X}<\mathrm{Y}$ ". The former option is exemplified by compositionality, which, however, exists only under conditions of strong idealization and/or simplification, as discussed in Subsection 4.1. The latter option is exemplified, with qualifications, by idioms and agreements as well as by perceptual gestalts, at least on one interpretation, as argued in Subsection 4.4.

\section{Acknowledgments}

As usual, I have benefitted from discussion with Anneli Pajunen. The meticulous editing by Jordan Zlatev has saved me from committing a couple of serious blunders.

\section{References}

Anttila, R. (1989 [1972]. Historical and comparative linguistics. Amsterdam: Benjamins. Apollonius Dyscolus. (1981). The syntax of Apollonius Dyscolus. Translated, and with an introduction by F. W. Householder. (1981). Amsterdam: Benjamins.

Aristotle. (1941). The basic works of Aristotle. Edited and with an introduction by R. McKeon. New York: Random House.

Beckerman, A., Flohr, H. \& Kim, J. (Eds). (1992). Emergence or reduction? Berlin: De Gruyter.

Bickel, B. \& Nichols, J. (2005). Exponence of selected inflectional formatives. Inflectional synthesis of the verb. In M. Haspelmath, M. S. Dryer, D. Gil \& B. Comrie (Eds.): The world atlas of language structures (pp. 90-97). Oxford: Oxford University Press.

Blake, B. (2001). Case, $2^{\text {nd }}$ ed. Cambridge: Cambridge University Press.

Chomsky, N. (1957). Syntactic structures. The Hague: Mouton.

Chomsky, N. 1965. Aspects of the theory of syntax. The MIT Press: Cambridge, Mass.

Croft, W. (2001). Radical construction grammar: Syntactic theory in typological perspective. Oxford: Oxford University Press.

Croft, W. (2003). Typology and universals, $2^{\text {nd }}$ ed. Cambridge: Cambridge University Press.

Durkheim, É. (1973 [1901]). Les règles de la méthode sociologique. Paris: Presses Universitaires de la France.

Erdman, E. \& Stover, D. (1991). Beyond a world divided: Human values in the brainmind science of Roger Sperry. Shambala: Boston.

Everett, D. \& Kern, B. (1997). Wari'. London: Routledge. 
Goldberg, A. (1995). Constructions: A construction grammar approach to argument structure. Chicago: The University of Chicago Press.

Goldberg, A. (2006). Constructions at work: The nature of generalization in language. Oxford: Oxford University Press.

Goldstein, E. B. (1989). Sensation and perception, 3rd ed. Pacific Grove, CA: Brooks/Cole Publishing Company.

Itkonen, E. (1978). Grammatical theory and metascience: A critical investigation into the methodological and philosophical foundations of 'autonomous' linguistics. Amsterdam: Benjamins.

Itkonen, E. (1983). Causality in linguistic theory: A critical investigation into the methodological and philosophical foundations of 'non-autonomous' linguistics. London: Croom Helm.

Itkonen, E. (1991). Universal history of linguistics: India, China, Arabia, Europe. Amsterdam: Benjamins.

Itkonen, E. (2003). What is language? A study in the philosophy of linguistics. University of Turku: Publications in General Linguistics 8.

Itkonen, E. (2005a). Analogy as structure and process: Approaches in linguistics, cognitive psychology, and philosophy of science. Amsterdam: Benjamins.

Itkonen, E. (2005b). Ten non-European languages: An aid to the typologist. University of Turku: Publications in General Linguistics 9.

Itkonen, E. (2008). The central role of normativity in language and linguistics. In J. Zlatev, T. Racine, C. Sinha \& E. Itkonen (Eds.): The shared mind: Perspectives on intersubjectivity (pp. 279-305). Amsterdam Benjamins.

Itkonen, E. (2011a). Papers on typological linguistics. University of Turku: Publications in General Linguistics 15.

Itkonen, E. (2011b [2003]). A case system with optional and interchangeable endings. In E. Itkonen (2011a), pp. 34-41.

Itkonen, E. (2011c [2008]). The blind spot of contemporary typological linguistics: The role of zero. In E. Itkonen. (2011a), pp. 91-95.

Itkonen, E. (2013). Functional explanation and its uses. In S. T. Bischoff \& C. Jany (Eds.): Functional approaches to language (pp. 31-69). Berlin: De Gruyter.

Itkonen, E. (2016). An assessment of (mentalist) cognitive semantics. Public Journal of Semiotics, 7.1, 1-42.

Itkonen, E. \& Pajunen, A. (2011 [2008]). A few remarks on WALS (= World atlas of language structures). In E. Itkonen (2011a), pp. 102-139.

Jackendoff, R. C. (1994). Patterns in the mind. New York: Basic Books.

Janssen, T. \& Redeker, G. (Eds.). (1999). Cognitive linguistics: Foundations, scope, and methodology. Berlin: Mouton de Gruyter.

Jespersen, O. (1922). Language: Its nature, development and origin. London: Allen \& Unwin.

Jespersen, O. (1965 [1924]). The philosophy of grammar. New York: Norton.

Keenan, E. (1976). Towards a universal definition of subject. In C. Li (Ed.): Subject and topic (pp. 303-334). New York: Academic Press.

Koestler, A. (1969 [1967]). The ghost in the machine. Harmondsworth: Penguin Books.

Körner, S. (1960). The philosophy of mathematics. London: Hutchinson.

Lakoff, G. (1987). Women, fire, and dangerous things. Chicago: The University of Chicago Press.

Langacker, R. (1987). Foundations of cognitive grammar, vol. I: Theoretical prerequisites. Stanford: Stanford University Press.

Langacker, R. (1991). Concept, image, and symbol: The cognitive basis of grammar. 
E. Itkonen

Berlin: Mouton de Gruyter.

Langacker, R. (2003). Construction grammars: cognitive, radical and less so. Paper presented at the ICL conference, Logroño.

Lehmann, T. (1994). Grammatik des Alttamil. Stuttgart: Franz Steiner.

Lukes, S. (1975 [1973]). Émile Durkheim. His life and work: A critical study. Harmondsworth: Penguin Books.

Nagel, E. (1961). The structure of science. New York: Harcourt, Brace \& World.

Pap, A. (1958). Semantics and necessary truth: An inquiry into the foundations of analytic philosophy. New Haven: Yale University Press.

Paul, H. (1920 [1880]). Prinzipen der Sprachgeschichte. Niemeyer: Tübingen.

Paulos, J. A. (1990 [1988]). Innumeracy: Mathematical illiteracy and its consequences. Harmondsworth: Penguin Books.

Phillips, D. C. (1976). Holistic thought in social science. London: Macmillan.

Plank, F. (1999). Split morphology: How agglutination and flexion mix. Linguistic Typology, 3, 279-340.

Roberts, J. (1997). GIVE in Amele. In J. Newman (Ed.): The linguistics of giving. Amsterdam: Benjamins.

Ryan, A. (1970). The philosophy of the social sciences. London: Macmillan.

Sampson, G. (1980). Making sense. Oxford: Oxford University Press.

Saussure, F. de. (1962 [1916]). Cours de linguistique générale. Paris: Payot.

Simon, H. (1962). The architecture of complexity. Proceedings of the American Philosophical Society, vol. 106, 467-482.

Sweetser, E. (1999). Compositionality and blending: Semantic composition in a cognitively realistic framework. In T. Janssen \& G. Redeker (Eds.), pp. 129-162.

Trubetzkoy, N.S. (1958 [1939]). Grundzüge der Phonologie. Göttingen: Vandenhoeck \& Ruprecht.

Velupillai, V. (2012). An introduction to linguistic typology. Amsterdam: Benjamins.

Whitney, W. D. (1979 [1875]). The life and growth of language. New York: Dover.

Winch, P. (1958). The idea of a social science and its relation to philosophy. London: Routledge.

Wittgenstein, L. (1958 [1953]). Philosophical investigations. Oxford: Blackwell.

Author address

eitkonen@utu.fi

About the author

Esa Itkonen was born in 1944. He is Professor Emeritus of General Linguistics (19822012) at the University of Turku, Finland; Dozent of Philosophy (1986-2012) at the University of Jyväskylä, Finland. Principal areas of interest: philosophy of linguistics, history of linguistics, linguistic typology 